\title{
LEITURA E AÇÃO DOCENTE NA PERSPECTIVA DA PEDAGOGIA HISTÓRICO-CRÍTICA
}

\author{
Rosangela Miola Galvão de OLIVEIRA ${ }^{1}$ \\ Sandra Aparecida Pires FRANCO ${ }^{2}$ \\ Elza Tie FUJITA ${ }^{3}$
}

Resumo: $O$ artigo apresenta a investigação acerca do contexto de leitura dos alunos de uma instituição de ensino pública do Estado do Paraná. Para tanto, foram aplicados diferentes instrumentos de geração de dados para propor posteriormente um projeto de intervenção em leitura. Utilizou-se como instrumentos de coleta os Índices de Desenvolvimento da Educação Básica (IDEB), a produção escrita dos alunos, entrevista com a equipe pedagógica e questionário socioeconômico. Tendo como parâmetro o conceito de totalidade para a compreensão das dificuldades dos estudantes optou-se pela Pedagogia Histórico-Crítica como base teórica para a produção dos dados. O estudo serve como justificativa para a implantação de Projeto de Intervenção em leitura e baseia-se nos resultados da análise que indicam uma carência de leitura dos discentes advindas do contexto escolar no qual estão imersos.

Palavras-chave: Leitura. Ação docente. Pedagogia histórico-crítica.

\section{Introdução}

Nos últimos anos, as temáticas educação e leitura vêm sendo tratadas e problematizadas por intelectuais do assunto, institutos de pesquisa, universidades e por órgãos internacionais como UNESCO (Organização das Nações Unidas para a Educação, a Ciência e a Cultura), CEPAL (Comissão Econômica para a América Latina e o Caribe), ONU (Organização das Nações Unidas). Estes órgãos apresentam propostas para a política educacional baseadas em dados coletados junto às instituições de ensino e, principalmente, das avaliações externas, no caso do Brasil, dos índices educacionais obtidos por avaliações. Entre elas, a Prova Brasil que direcionam inclusive a reformulações do currículo escolar.

Sabendo que muitas vezes os dados coletados pouco refletem as realidades escolares, o trabalho pretende apresentar a importância de conhecer o objeto de estudo,

\footnotetext{
${ }^{1}$ Mestre em Educação. UEL - Universidade Estadual de Londrina. Londrina - PR - Brasil. 86057-970 rmgalvao2012letras@gmail.com

2 UEL - Universidade Estadual de Londrina. Londrina - PR - Brasil. 86057-970 sandrafranco26@hotmail.com

${ }^{3}$ Mestranda em Educação. UEL - Universidade Estadual de Londrina. Londrina - PR - Brasil. 86057-970

- elzafj@hotmail.com
} 
no caso o déficit de leitura na Educação Básica, antes de planejar uma intervenção, que venha a contribuir para a transformação da realidade enfrentada.

$\mathrm{Na}$ constituição do projeto de intervenção, primeiro organizou-se uma equipe de colaboradores e bolsistas integrados ao Observatório da Educação - OBEDUC, que é um Programa do Governo Federal (BRASIL, 2006) destinado a fomentar as pesquisas em Educação, à integração Universidade-Escola e no desenvolvimento de projetos de pesquisa que articulam a necessidade da teoria na prática docente.

Após a constituição do grupo responsável pelo projeto de intervenção, o segundo passo foi de compor um quadro analítico sobre a escola investigada. Para tanto, partiuse do cenário externo, da visão caótica sobre o objeto, com os resultados da Prova Brasil, para depois observar o contexto escolar interno, para que ao final se tenha uma visão de totalidade da carência de leitura dos estudantes.

$\mathrm{O}$ artigo foi dividido em três seções. Na primeira seção expõe o conhecimento sobre o IDEB a fim de conhecer mais sobre este instrumento de avaliação externa. Na segunda seção são explanadas as considerações da Pedagogia Histórico-Crítica para a ação docente e na terceira seção estão expostos os resultados das coletas dos instrumentos.

\section{Índice de Desenvolvimento da Educação Básica (IDEB)}

O IDEB (BRASIL, 2007) surgiu com o intuito de verificar a qualidade do ensino nas instituições educacionais. O índice possui como base para seus cálculos o índice de aprovação escolar, obtido por meio do Censo Escolar realizado todos os anos pelo Instituto Nacional de Estudos e Pesquisas Educacionais Anísio Teixeira - INEP e o desempenho dos estudantes em avaliações padronizadas (Prova Brasil ou Saeb) (BRASIL, [20--]). A combinação destes dois fatores possui a intenção de observar o tempo de conclusão de uma etapa de ensino (reprovação, aprovação e abandono), e também os conhecimentos adquiridos pelos alunos no período de formação na Educação Básica, que pode ser dividido em: primeira fase da Educação Básica (do $1^{\circ}$ ao $5^{\circ}$ ano escolar); segunda fase (do $6^{\circ}$ ao $9^{\circ}$ ano escolar) e Ensino Médio Regular ( $1^{\text {a }}$ a $3^{\text {a }}$ série) com o objetivo de alcançar 6,00 pontos (em uma escala de zero a dez) em 2022, como média nacional.

A taxa média de aprovação dos estudantes na etapa de ensino mais os desempenhos dos alunos nos exames padronizados fornecem os índices do IDEB de cada escola. Este valor é apresentado a cada dois anos e serve como medida para 
políticas de intervenção do Governo Federal. Para o melhor entendimento deste indicador, o trabalho de Fernandes (2007) apresenta a formação do IDEB e dos indicadores que o compõem.

O Saeb, um dos componentes do IDEB, é composto por três avaliações: Ana, Aneb e Anresc (Prova Brasil) (BRASIL, 2011). A Avaliação da alfabetização - Ana é destinada para alunos do $3^{\circ}$ ano do Ensino Fundamental, sendo censitária e com o objetivo de investigar o nível de alfabetização dos alunos desta fase escolar. A Avaliação Nacional da Educação Básica - Aneb, mede o desempenho dos estudantes a nível amostral, por isso seu resultado fornece índices somente a nível de Brasil, regiões e unidades da Federação e não específicos por municípios. Também promove estudos que verificam os sistemas e redes de ensino por meio de questionários, desde 1995 (BRASIL, 2008). A Avaliação Nacional do Rendimento Escolar - Anresc, conhecida como Prova Brasil, é aplicada a cada dois anos. Na sua formulação estão questões sobre: Língua Portuguesa (foco na leitura) e Matemática (foco na resolução de problemas). As avaliações da Prova Brasil se destinam aos alunos dos últimos anos do Ensino Fundamental Fase I ( $5^{\circ}$ ano) e da Fase II ( $9^{\circ}$ ano) da rede pública de ensino. O objetivo desta avaliação segundo o órgão competente está além da busca por melhor qualidade de ensino, mas também "[...] redução de desigualdades e democratização da gestão do ensino público; buscar o desenvolvimento de uma cultura avaliativa que estimule o controle social sobre os processos e resultados do ensino". (BRASIL, 2008, p.8).

Após um longo histórico de propostas de avaliações e implantação de programas avaliativos no Brasil que datam de 1985, o Saeb instituído em 1988, tinha como função proporcionar ao Governo subsídios para a formulação, reformulação e monitoramentos de políticas públicas (BRASIL, 2008). A primeira avaliação ocorreu em 1990. Em 2005, nasce a Prova Brasil e desde 2007, Saeb e Prova Brasil trabalham em conjunto, fornecendo dados censitários ao INEP, devido ao uso da mesma metodologia aplicada em suas avaliações. A Prova Brasil está atrelada aos municípios e o Saeb às unidades da federação e para o país.

Sobre a compreensão leitora, a Prova Brasil procura trazer em suas questões um arcabouço de textos de diferentes gêneros com complexidades diversas e temas variados. Esta diversidade é compreendida pelo órgão que compõe a Prova Brasil como um recurso para avaliar os diferentes níveis de competência leitora dos alunos, pois "o importante é entender que os textos que são lidos pelos estudantes que realizam a Prova 
Brasil, foram analisados previamente e, quando o aluno acerta ou erra cada item, sabemos em que nível de leitura se encontra." (BRASIL, 2008, p.12). A proficiência é medida em dez níveis, em uma escala que vai de 0 a 500 . O foco pela leitura na avaliação da Língua Portuguesa é justificado por considerar esta competência importante para a formação do cidadão, para eles a leitura “[...] é fundamental para o desenvolvimento de outras áreas do conhecimento e para o consequente exercício da cidadania”. (BRASIL, 2008, p.21).

\section{A pedagogia histórico-crítica e a ação docente}

Tomando como referência os pressupostos filosóficos do Materialismo Histórico Dialético, a Pedagogia Histórico-Crítica parte do pressuposto de que o sujeito se constitui a partir das relações sociais que são estabelecidas mediante ao contexto social no qual está inserido. Para a Pedagogia Histórico-Crítica, a educação é uma forma de acesso à cultura intelectual que é desenvolvida de forma sistemática e intencional, no qual o acesso ao saber sistemático é o que permite a participação na sociedade.

Saviani e Duarte (2012) explicam que a educação tem por finalidade a formação humana enquanto processo. Desta forma, para que o processo de formação humana se concretize por meio da educação se torna necessário considerar o homem histórico enquanto síntese das relações sociais. Destarte, Saviani (2003) destaca que a instituição escolar tem como objetivo principal produzir " [...] direta e intencionalmente, em cada indivíduo singular, a humanidade que é produzida histórica e coletivamente pelo conjunto dos homens." (SAVIANI, 2003, p.13).

Sendo assim, a escola tem a função de socializar intencionalmente a todos os indivíduos elementos culturais necessários à constituição da humanidade. Neste contexto, para que uma escola desempenhe bem sua função é necessário que se priorize a transmissão-assimilação do saber sistematizado. No que concerne à linguagem, para Vigotski (2010, p.125) “[...] diferentemente do ensino da linguagem falada, no qual a criança pode se desenvolver por si mesma, o ensino da linguagem escrita depende de um treinamento artificial", isto revela a necessidade de um processo de ensino e aprendizagem mais sistematizado realizado pelas instituições escolares. Sendo que "[...] a leitura e a escrita devem ser algo de que a criança necessite.” (VIGOTSKI, 2010, p.143). Assim, somente ocorrerá a apropriação da linguagem quando o aluno puder relacionar que o saber escolar é pré-requisito para outros aprendizados ao longo da vida. 
Desta forma, a leitura se torna instrumento de acesso dos alunos aos conhecimentos científicos sistematizados pelo professor. Neste contexto, ao docente cabe o trabalho com a leitura que desvela as várias intencionalidades dos discursos, que podem ser denominadas segundo Saviani e Duarte (2012) de dimensões. Os entendimentos das dimensões dos discursos proporcionam ao discente uma visão mais ampla, o ir além da superficialidade do texto, pois revela nas produções textuais as dimensões tais como: históricas, políticas, econômicas, psicológicas, éticas, culturais, que contribuem para o entendimento do todo, ou seja, do saber que inter-relaciona o contexto aos múltiplos fatores que o envolvem. Sendo assim, a leitura na perspectiva da Pedagogia Histórica Crítica promove a inserção do sujeito ao meio em que vive, sendo esta posição de cunho participativo e não contemplativo.

Saviani e Duarte (2012) enfatizam a importância da transmissão de conceitos clássicos, ou seja, os conteúdos que permanecem historicamente e que servem de referências para as gerações futuras enquanto elemento fundamental para o processo de humanização do sujeito. $\mathrm{O}$ acesso ao clássico permite compreender o contexto no qual o homem está inserido, “[...] o que tem grande valor educativo, já que a educação não é outra coisa senão o processo por meio do qual se constitui em cada indivíduo a universalidade própria do gênero humano." (SAVIANI; DUARTE, 2012 p.31). Importante salientar que o trabalho educativo deve ser uma atividade intencional e dirigida e com uma finalidade específica a fim de promover o desenvolvimento psíquico do sujeito.

Saviani e Duarte (2012) explicam que a apreensão do conhecimento do todo compreende dois momentos no qual parte-se do conhecimento empírico, ou seja, a visão sincrética, caótica e imediata do objeto para a partir desta representação por meio da análise se chegar às abstrações e as determinações mais simples. Sendo assim, é por meio da mediação escolar que ocorre a passagem do saber cotidiano para o saber sistematizado por meio de um movimento dialético no qual a ação pedagógica possibilita “[...] que se acrescentem novas determinações que enriquecem as anteriores e estas, portanto, de forma alguma são excluídas.” (SAVIANI, 1995, p.27).

Nesta perspectiva Saviani (2000) enfatiza que o primeiro passo deve ser a prática social comum do qual participam professor e aluno a fim de articular a prática pedagógica com o contexto social no qual os alunos estão inseridos. O segundo passo consiste na problematização do conteúdo, no qual se procura detectar as questões que necessitam ser resolvidas e o conhecimento que é necessário dominar. A seguir, o 
docente deverá instrumentalizar o aluno por meio de elementos teóricos e práticos para que o mesmo possa equacionar os problemas detectados inicialmente e chegar a "catarse" que seria a incorporação dos elementos culturais que permitirá ao aluno transformar o meio social pela prática social. Este método consiste em levar o aluno da síncrese à síntese por meio da mediação da análise.

Assim, o educador deve ter uma visão clara e sistematizada acerca do ponto de partida, dos objetivos que pretende alcançar e dos meios que serão utilizados para atingir levar o aluno da síncrese à síntese. É de suma importância planejar as ações educativas, pois o ato educativo envolve intenções e intencionalidade, ou seja, contribuir para o desenvolvimento pleno do educando no que concerne a uma formação humana para o exercício conscientemente da cidadania a favor da democratização da sociedade.

\section{Contexto escolar e a necessidade da leitura}

Para entender o contexto escolar da instituição pesquisada, primeiro foram analisados os índices do IDEB da escola e os resultados alcançados pelos alunos na Prova Brasil nos anos de 2009 e 2011 subsequentemente. Com relação ao IDEB, a instituição de ensino apresentou os seguintes índices para os Anos Finais do Ensino Fundamental: 2,6 e 3,3; sendo estes índices bem inferiores à média do município: 4,1 e 4,0. As notas da Prova Brasil em Língua Portuguesa foram: 221,96 e 226,27; também inferiores à média do município: 252,92 e 248,70. As notas alcançadas pelos alunos desta instituição de ensino revelam um avanço de nível na escala de proficiência, do nível 4 para o nível 5, ou seja da escala de 200 a 225 do nível 4 para a escala de 225 a 250 do nível 5. Em matéria de aprendizado, é possível considerar que os alunos além dos conhecimentos anteriores também apresentam melhorias no uso da pontuação, na inferência da finalidade do texto; distinção entre fato e opinião; distinção do sentido metafórico de uma expressão; reconhecem efeitos de ironia; interpretam textos gráficos. Lembrando que ao todo são dez níveis da escala de proficiência em Língua Portuguesa na segunda fase do Ensino Fundamental. Portanto, os alunos ainda possuem um grande caminho na apropriação de conhecimentos, pois os conhecimentos exigidos pela Prova Brasil são de cunho básico.

No decorrer dos últimos anos, as avaliações em larga escala vêm servindo de base para a implementação de políticas educacionais na tentativa de superar os resultados negativos que se configura no cenário educacional. Neste contexto, o 
OBEDUC (BRASIL, 2006), com base nos dados do INEP (BRASIL, 2011), tem como proposta analisar e compreender os indicadores divulgados pelo IDEB (BRASIL, 2007), a fim de identificar os problemas e dificuldades de aprendizagem para posteriormente propor ações, visando a práxis educacional, integrando assim, teoria e prática no trabalho pedagógico com o objetivo de promover a formação humana dos alunos no contexto escolar. No entanto, o foco deste trabalho está em conhecer e analisar o contexto de uma das escolas participantes, denominada Escola A, localizada no distrito de uma cidade do norte do Paraná, a fim de propor estratégias de ensino e aprendizagem com o objetivo de contribuir para a construção do conhecimento científico do aluno, com ênfase na leitura. A produção escrita realizada pelos alunos da Escola A foi que norteou a escolha desta instituição para a investigação.

No primeiro contato, procurou-se conhecer o contexto educacional e social no qual a instituição está inserida e assim realizar um processo investigativo e reflexivo sobre os principais problemas enfrentados pelos educadores daquela instituição. Nesta perspectiva, Marx (1982) explica que a primeira premissa que devemos considerar ao analisar determinado contexto é a existência humana, ou seja, a constatação da organização física, a sua relação com o meio físico e o modo como o homem se modifica e altera o meio na produção da sua vida material. Salientamos que a práxis educativa só pode ser concretizada por meio da formação do ser consciente na sua condição social e material que age intencionalmente, visando à transformação do contexto no qual está inserido.

No aspecto geral, o contato com a escola envolvida revelou um panorama das principais dificuldades enfrentadas pela comunidade escolar. Percebeu-se que as dificuldades relacionadas ao contexto social, econômico, cultural e de violência acabam afetando de forma direta e indiretamente o contexto escolar. Essas percepções foram reveladas pela equipe pedagógica que relatou por meio das observações nos livros de registros dos alunos, um grande envolvimento dos discentes com drogas, atividades laborais no campo, poucas atividades culturais. Marx (1982) explica que é a produção material que condiciona as concepções, ideias e as representações dos indivíduos, ou seja, os indivíduos são constituídos a partir do seu processo de desenvolvimento perceptível empiricamente em determinadas condições no qual a consciência é que determina a vida.

A entrevista com a equipe pedagógica revelou que um grande número de alunos é oriundo da zona rural e de famílias humildes com pouco grau de instrução. Os 
principais problemas que a instituição enfrenta estão relacionados à condição socioeconômica dos alunos, à alimentação, desestrutura familiar, violência doméstica e alto índice de analfabetismo entre os pais de alunos.

Diante desses fatores, recorremos aos pressupostos de Savieni e Duarte (2012), o qual lembra que o contexto educacional é apenas um dos complexos que compõe o sujeito na vida em sociedade, sendo, portanto, necessário analisar o contexto social em uma perspectiva dialética, ou seja, um processo contraditório e heterogêneo no qual somente por meio da análise das possibilidades do vir a ser, que se torna possível propor estratégia para o dever-ser.

Com relação ao questionário socioeconômico, no momento da aplicação do mesmo estavam presentes 38 alunos de duas turmas do $8^{\circ}$ ano. As questões versaram sobre aspectos econômicos e sociais dos estudantes, como também o contato dos mesmos com a leitura. Sobre o nível de instrução dos pais e ou responsáveis, a grande maioria, 31 alunos, respondeu não saber o grau de instrução dos responsáveis, sendo que apenas um apontou que o pai possui o ensino superior incompleto, sendo os demais distribuídos em: cinco com ensino fundamental completo, três sem escolaridade, 28 com o ensino fundamental incompleto, três ensinos médio incompleto, quatro ensino médio completo.

Questões relacionadas ao contato dos alunos com os meios de comunicações revelam que 16 alunos não possuem computador, oito possuem computador sem internet e 14 possuem computador com internet. $\mathrm{O}$ meio de informação mais acessado pelos alunos é a televisão com 29 respostas positivas para esta mídia, contra uma de rádio e oito de internet. Todos os alunos assinalaram que a escola possui biblioteca, mas apenas 21 frequentam este ambiente para leitura, revelando que este espaço cumpre com sua principal função, a de disseminar e oportunizar o acesso aos livros. Sobre projetos de leitura, 31 alunos revelam que não existe um projeto específico para esta temática. Dentre as disciplinas que proporcionam aulas de leitura foram lembradas as: de Português e de História.

$\mathrm{Na}$ busca por ações na realidade escolar dos alunos participantes, verificou-se a carência da leitura dos alunos por meio da análise de uma produção escrita. As análises das produções possuem o objetivo de verificar quais necessidades reais dos alunos em relação à leitura e a escrita, pois somente desta forma é que se pode garantir a efetivação de projetos mais significativos aos alunos. 
De um total de 38 produções escritas foram transcritas literalmente as frases mais representativas do desvio da norma culta da Língua Portuguesa. A atividade desenvolvida consistia na produção de uma dissertação com o tema "Minha Vida". A proposta teria o objetivo de revelar a historicidade familiar do aluno, o meio social em que vive e as expectativas dos mesmos com relação ao trabalho.

O passeio que deceja fazer ir praia, quando eu creser eu quero ser adevogada. (Aluno A).

A minha mãe e dular e a disiprina que eu mas gosto e artes. (Aluno B).

[...] e vai que arprica a jengesão nas pessoas e as pessoas pega uma duenca. (Aluno C).

[...] sem as vacas [...] os mercados não ia ezistir leites. [...] os cientistas não ia esprementar as vacinas. (Aluno D).

Verifica-se por meio das frases que o aluno A tem dificuldades para estruturar a frase, ele escreve como se fala. O aluno B não assimilou as regras de pontuação, transcreve a fala e aglutina palavras que deveriam estar separadas. $\mathrm{O}$ aluno $\mathrm{C}$ transfere para a escrita a variação linguística que pertence, com inserção de letras que dificultam a compreensão da frase. O aluno D apresenta dificuldade em realizar a flexão em número, ou seja, não flexiona o verbo em relação ao sujeito. Estas distorções são características de alunos que possuem pouco contato com a leitura e a escrita, em geral os discentes transcrevem para o texto da mesma forma que falam.

Neste contexto de carência a investigação propõe como ação docente a realização de Projeto de Intervenção em leitura, a fim de proporcionar a transformação da realidade de dificuldades dos estudantes com o ato de ler. Para Rocha e Aguiar (2003) pode-se considerar o projeto de intervenção sob o viés da pesquisa participativa, que utiliza a ação em uma realidade concreta com o propósito de modificar e entender os fatores e situações presentes nesta realidade. Para estas estudiosas "[...] a pesquisaintervenção consiste em uma tendência das pesquisas participativas que busca investigar a vida de coletividades na sua diversidade qualitativa, assumindo uma intervenção de caráter socioanalítico.” (ROCHA; AGUIAR, 2003, p.66). Assim, os problemas não são entendidos em sua objetividade, mas a partir do universo de fatores aos quais estão inseridos de forma a entendê-los em sua subjetividade. 


\section{Considerações finais}

Os índices educacionais podem revelar a necessidade de um olhar diferenciado à situação. A verificação da necessidade real pode ser comprovada por intermédio de investigações feitas pelos próprios professores, que a partir de então são capazes de elaborar projetos de intervenção baseados em teorias que contemplem a visualização deste ser em construção. A teoria utilizada reflete o movimento do pensamento, por isso serve aos propósitos de uma formação integral. Direcionar a prática pedagógica para a transformação da realidade que nos cerca se torna essencial quando o objetivo é a formação integral do aluno. Quando se trabalha com o objetivo de desenvolver o pensar, o aluno não fica restrito à resolução de provas externas, mas passa a refletir sobre sua ação enquanto ser humano. A transformação vai além de necessidades pontuais, ela atinge a vida como um todo. A leitura neste contexto se faz necessária, pois representa ao aluno uma forma de inserção ao conhecimento científico, a fim de prepará-lo para a realização de atividades mais complexas e que exijam maior reflexão, ou seja, a formação integral da consciência, característica fundamental e advinda das interações sociais. A partir deste arcabouço de entendimento de como está posto o contexto escolar, os projetos de intervenção serão construídos e conduzidos pela equipe participante, formada por professores bolsistas, alunos da graduação bolsistas, alunos do mestrado bolsistas e professores da Universidade.

\section{READING AND ACTION TEACHING IN PERSPECTIVE OF HISTORICAL AND CRITICAL PEDAGOGY}

Abstract: The article presents research about the context of students' reading of a public educational institution of the State of Paraná. Therefore, we applied different instruments of data generation later to propose a read on intervention project. It was used as collection instruments the Basic Education Development Index (IDEB), written production of students, interview with the teaching staff and socioeconomic questionnaire. Having as parameter the concept of totality to understand the difficulties of the students opted for the Historical-Critical Pedagogy as a theoretical basis for the production of data. The study serves as a justification for the implementation of reading Intervention Project and is based on the results of the analysis indicate a lack of reading arising students of the school context in which they are immersed.

Key words: Reading. Teaching action. Historical-critical pedagogy. 


\section{REFERÊNCIAS}

BRASIL. Instituto Nacional de Estudos e Pesquisas Educacionais Anísio Teixeira INEP. Saeb. Brasília: INEP, 2011. Disponível em:

<http://portal.inep.gov.br/web/saeb/aneb-e-anresc>. Acesso em: 30 jun. 2016.

BRASIL. Ministério da Educação. Plano de Desenvolvimento da Educação: Prova Brasil: ensino fundamental: matrizes de referência, tópicos e descritores. Brasília: MEC, SEB; INEP, 2008.

BRASIL. Instituto Nacional de Estudos e Pesquisas Educacionais Anísio Teixeira INEP. Ideb - resultados e metas. Brasília: INEP; MEC, 2007. Disponível em: <http://ideb.inep.gov.br/>. Acesso em: 30 jun. 2016.

BRASIL. Ministério da Educação. Observatório da educação. Brasília: CAPES, 2006. Disponível em: <http://www.capes.gov.br/educacao-basica/observatorio-da-educacao>. Acesso em: 30 jun. 2016.

BRASIL. Ministério da Educação. Prova Brasil - apresentação. Brasília: MEC, [20--]. Disponível em: <http://portal.mec.gov.br/prova-brasil〉. Acesso em: 30 jun. 2016.

FERNANDES, R. Índice de Desenvolvimento da Educação Básica (IDEB). Brasília: Instituto Nacional de Estudos e Pesquisas Educacionais Anísio Teixeira - INEP, 2007. (Série Documental. Textos para Discussão, 26).

MARX, K.; ENGELS, F. Obras escolhidas. Tomo I. Lisboa: Avante, 1982.

ROCHA, M. L.; AGUIAR, K. F. Pesquisa-intervenção e a produção de novas análises. Psicologia: Ciência e Profissão, Brasília, v.23, n.4, p.64-3, 2003.

SAVIANI, D. Escola e democracia: teorias da educação, curvatura da vara, onze teses sobre educação e política. 33.ed. rev. Campinas: Autores Associados, 2000.

SAVIANI, D. Pedagogia histórico-crítica: primeiras aproximações. Campinas: Autores Associados, 2003.

SAVIANI, D. Sobre a natureza e especificidade da educação. In: SAVIANI, D. Pedagogia histórico-crítica. 5.ed. Campinas: Autores Associados, 1995. p.9-28.

SAVIANI, D. Sobre a natureza e especificidade da educação. Em aberto, Brasília, v.3, n.22, p.1-6, jul./ago. 1984.

SAVIANI, D.; DUARTE, N. A formação humana na perspectiva histórico-ontológica. In: SAVIANI, D.; DUARTE, N. Pedagogia histórico-crítica e luta de classes na educação escolar. Campinas: Autores Associados, 2012. p.13-35.

VIGOTSKI, L. S. Formação social da mente. São Paulo: Martins, 2010. 